\title{
EDUCAÇÃO E SAÚDE VISANDO À CIDADANIA: Práxis grupal de enfermeiras 1
}

\author{
EDUCATION AND HEALTH AIMING AT CITIZENSHIP: NURSES GROUP PRAXIS.
}

\author{
Carlos Bezerra de Lima ${ }^{2}$ \\ Suely de Souza Baptista ${ }^{3}$
}

\begin{abstract}
RESUMO: Estudo realizado em Comitê Comunitário, na comunidade N.S.Aparecida, periferia de João Pessoa - PB. São objetivos: caracterizar a prática das enfermeiras ali envolvidas e discutir o modo de realização dessa prática. O material analisado constou de depoimento de oito moradores da comunidade e quatro enfermeiras, coletado mediante entrevista semi-estruturada, numa abordagem qualitativa. Teve como foco de discussão as questões de educação e saúde, na perspectiva do exercício da cidadania. Nas representações dos sujeitos participantes do estudo, educação aparece como questão dinâmica e implica conscientização, uma questão de vida; Saúde é compreendida sob três óticas: a do bem - estar, a do sofrimento e a do equilíbrio biológico. A perspectiva do exercício da cidadania se revela, ora em forma de conformismo, através do silêncio ou da resignação, ora como resistência, através da manifestação do ideal e da coragem de ir à luta por melhores condições de vida.
\end{abstract}

UNITERMOS: Enfermagem - Educação e saúde - Cidadania.

ABSTRACT: This study was run in a community committee of Nossa Senhora da Aparecida, a surrounding city of Joao Pessoa, Paraiba. It aimed at characterizing nursing practice there and discussing its occurrence. The analysis was run based on eight inhabitants and four nurses speeches through semistructured interviews whose data were collected qualitatively. It focused on the discussion which evolved from questions regarding to education and health from the perspective of exercising citizenship. In the participants of the study representations, education seemed dynamic and implied awareness ... a question of life. Health is comprehended under 3 points of view: the one of welfare, the one of suffering and the one of biological balance. The perspective of citizenship exercise reveals itself sometimes as conformism, through silence or resignation and sometimes as resistance, through the ideal manifestation and courage for fighting for better life condition.

KEYWORDS: Nursing - Education and health - Citizenship.

\footnotetext{
${ }^{1}$ Trabalho apresentado no $9^{\circ}$ SENPE - Vitória-ES, 1997.

2 Professor Adjunto do Departamento de Enfermagem Médico-Cirúrgica e Administração / UFPB; Doutor em enfermagem.

${ }^{3}$ Doutora em Enfermagem e Professora Adjunta da Escola de Enfermagem Anna Nery, UFRJ.
} 


\section{INTRODUÇÃO}

Teoricamente, as políticas sociais podem ser definidas como um conjunto de medidas adotadas pelo Estado, cuja meta é atender às necessidades das populações carentes, prioritariamente nas áreas de educação, saúde e moradia. Têm como componentes básicos as politicas de saúde e educação que representam as práticas concretas do Estado.

Na realidade, os programas oficiais nesta área têm representado ações isoladas, sem definição de uma politica social de conjuntura, sem dotação de recursos, estratégias bem estruturadas e ações integradas, conseqüentemente ineficientes.

A atual situação de saúde e educação da população brasileira é motivo de preocupação para a comunidade acadêmica e para a sociedade, de um modo geral. A questão agrava-se ainda mais quando focalizamos as populações de baixa renda, particularmente aquelas fixadas na região Nordeste. Esta região apresenta profundas marcas de subdesenvolvimento e pobreza, resultantes de questões históricas, políticas e ecológicas. Tem como um dos seus componentes o Estado da Paraiba, um dos menores e mais pobres estados brasileiros, onde são pagos os menores salários da região e são registrados os maiores indices de miséria, com 41,54\% de analfabetos. Apresentou, em 1991, um rendimento médio de 1,64 salários-minimos, inferior ao da região Nordeste, que foi de 1,89, e ao rendimento médio do Pais, de 3,42 salários-minimos, (Coelho, 1996: 17).

Um estudo realizado pelo Instituto de Desenvolvimento Municipal e Estadual mostrou que a expectativa de vida na Paraiba, em 1993, era de 55,4 anos para as mulheres e 51,7 anos para os homens, (Paraiba, 1995: 01). Tais circunstâncias situam sua população em nivel de subdesenvolvimento, intensificam as desigualdades sociais e afetam a saúde fisica e mental, pois há uma relação estreita e de caráter progressivo entre renda familiar e saúde,

(Fernandes, 1996, p. 43).

Apesar de recordista em pobreza, a região Nordeste concentra grande parte dos recursos ali existentes na esfera privada. Isto significa que o acesso aos bens e serviços sociais, inclusive à saúde, dá-se mediante uma relação de troca; ou seja, através de um ato de compra, o individuo tem acesso à saúde e à educação como uma mercadoria qualquer. Face a tais contradições, a situação de saúde das pessoas que procuram ajuda no Comitê, cenário desta pesquisa, é bastante critica, em decorrência do próprio estado de pobreza generalizada, em que sofrem os agravos da falta de emprego e de saneamento básico, da precariedade das moradias e da desnutrição.

Um sério complicador da qualidade de vida e saúde destas populações é a falta de educação básica que as qualifique para cuidar da saúde, para o trabalho e para a luta em prol de melhores condições de vida. Consideramos, por educação básica, o ensino fundamental, assegurado na Constituição Federal como direito de todos e dever do Estado, "visando ao pleno desenvolvimento da 
pessoa, seu preparo para o exercício da cidadania e sua qualificação para o trabalho"(CONSTITUIÇÃO FEDERAL, 1988, cap. III, art. 205).

Nossa Constituição Federal define explicitamente a educação como instrumento de construção da cidadania. No entanto, a estratégia básica do sistema de ensino brasileiro é a tecnologia, substituindo a dimensão política da educação pela dimensão tecnológica (Demo, 1992: 23). Noutras palavras, ao invés de constituir-se em ferramenta na construção de uma consciência crítica, nossa educação tem formado gente submissa, obediente ao autoritarismo técnico, isoladamente da questão da cidadania (Gadotti, 1991, p: 53).

Outra contradição no sistema brasileiro de educação é que a Constituição Federal garante a educação como direito de todos $e$, na realidade, destina-se efetivamente a determinadas camadas sociais. Na prática, o ensino público já foi privatizado, pois somente aqueles que dispõem de recursos financeiros para pagar a escola conseguem formar seus filhos. A rede de ensino público e gratuito está desqualificada, em termos da qualidade do ensino que oferece à coletividade, bem inferior ao que oferece a rede privada e em conseqüência às políticas governamentais de desasistência à educação.

\section{METODOLOGIA}

Trata-se de um estudo de caso, cujo objeto de análise são os depoimentos de oito clientes, pessoas que procuraram ajuda em um Comitê Comunitúrio e permaneceram participando dos trabalhos nele desenvolvidos, e quatro enfermeiras que ali trabalham como voluntárias. O Comitê está sediado em uma comunidade periférica da cidade de João Pessoa - PB, a comunidade Nossa Senhora Aparecida, localizada no bairro do Cristo Redentor. As enfermeiras integram um grupo de pessoas voluntárias que desenvolvem um trabalho de promoção social e, no caso particular, o trabalho dessas enfermeiras está centrado nas questões saúde e educação e desenvolve-se na perspectiva do exercício da cidadania.

Procuramos apreender aquela realidade e compreender seus componentes, a partir dos depoimentos de nossas entrevistadas. $\mathrm{Na}$ composição desses sujeitos foi exigido que a pessoa tivesse participação efetiva nos trabalhos do comitê; tanto no caso das enfermeiras como em relação às clientes.

Por tratar-se de uma pesquisa que envolve seres humanos, observamos os aspectos éticos disciplinados pela Resolução 01/ 88 do Conselho Nacional de Saúde/ MS, assegurando aos participantes informações sobre os objetivos da pesquisa, o livre consentimento e a liberdade de desistir da participação, se em qualquer momento assim desejassem.

O material para análise foi coletado mediante a técnica de entrevista semiestruturada e teve como fio condutor um roteiro previamente elaborado, contendo questões inerentes aos objetivos propostos para o estudo. Esta coleta constou de dois momentos: no primeiro, nós fizemos um contato com 
enfermeiras e clientes, mediante diálogo informal, no intuito de confirmar sua participação na pesquisa, agendar as entrevistas e criar um clima favorável para sua realização; no segundo, ocorreu o desenvolvimento das entrevistas que duraram cerca de quinze minutos cada. Ao término das mesmas, ficamos à disposição das entrevistadas para esclarecer possiveis dúvidas acerca do estudo ou de outro assunto de seu interesse.

A organização, apresentação e discussão do material coletado foram realizadas de maneira descritiva, a partir da literatura que revisamos e do ângulo de nossa visão.

\section{ANÁLISE DO MATERIAL}

No desenvolvimento das análises, procuramos centrar o nosso foco de discussão sobre as questões educação e saúde. Elas compõem a estrutura social, existem na realidade concreta inter-relacionadas com os diferentes determinantes do desenvolvimento social e têm participação direta na determinação da qualidade de vida das pessoas, em sua singularidade e como grupos sociais.

Procuramos analisar as representações de educação de nossas entrevistadas, ancorando-as em teorias que concebem a educação como questão dinâmica; não apenas de sala de aula, de créditos e livros didáticos mas, fundamentalmente, uma questão de vida. Isso está claro na visão das clientes quando afirmam que "educação é a formação das pessoas; ensina às pessoas como viver e como resolver os problemas que dificultam a vida"(NAC); "educação é ajudar as pessoas a descobrir o mundo e a viver nele"(JSL).

Nas representações das enfermeiras nós também encontramos nexos com esta concepção política de educação em vários momentos das entrevistas. A enfermeira (1), ao falar do seu trabalho, afirmou: "desejo que essas pessoas descubram que elas podem e lutem para construir uma vida melhor para si, para seus familiares e para seus vizinhos". Assim concebida, a educação é uma questão de tomada de consciência do indivíduo enquanto sujeito social, cujo destino coletivo depende de si; implica as questões relacionadas com sua opinião, seu comportamento, suas decisões.

Esta visão de educação é referendada, na prática, a partir da descrição que uma cliente faz, afirmando que "enquanto a gente trabalha, muita coisa se conversa; se fala de saúde, de alimentos, de política, de religião, dos problemas da comunidade. O resultado disso é que a gente vai fazendo amizade, vai aprendendo umas com as outras" (GPS). A partir dessas informações já se percebe sinais de mudança no processo em estudo, fruto de um trabalho educacional informal. Trata-se, portanto, de algo que está acontecendo na relação de um grupo que tem "como saber, como crença, aquilo que é comunitário como bem, como trabalho, como vida"(Brandão, 1990: 10). 
Uma análise da educação enquanto questão de vida remete-nos às concepções de Paulo Freire, para quem a educação faz parte da vivência do diaa-dia e deve constituir-se em instrumento de transformação, de forma que possa ajudar as pessoas a se descobrirem e a desenvolverem suas potencialidades de crescimento individual e como sujeito coletivo. Assim concebida, a educação implica uma busca por parte daquela pessoa que se descobre sujeito de sua própria educação. Essa busca não se dá de forma isolada, na individualidade de cada um, realiza-se na relação com outras pessoas que têm objetivos comuns (Freire, 1979, p. 27).

Este tipo de educação é construído dentro de uma pedagogia dialética, na qual a formação se dá pela tomada de consciência coletiva, construída em um processo dialógico, em que todos refletem juntos sobre os problemas da coletividade e todos têm coisas a dizer e a ouvir (Gadotti,1992, p. 49). Neste processo, as relações interpessoais não acontecem de maneira simples e homogênea: elas tomam formas complexas e contraditórias, estão inseridas no próprio processo de vida das pessoas.

Esta relação complexa e contraditória pode ser percebida nos depoimentos das enfermeiras, pois, ao mesmo tempo em que valorizam e utilizam o saber existente na comunidade como ponto de partida para as discussões nos grupos de trabalho, elas qualificam esse mesmo conhecimento como rude e inferior. Tornam-se complexas, a partir do juízo que as enfermeiras fazem do saber popular, evidenciando-se uma assimetria na relação dos saberes. Vejamos tais depoimentos: "os conhecimentos que a comunidade tem ajudam na convivência e no saber de cada um; o que a gente precisa é melhorar estes conhecimentos" (enfermeira 2); "às vezes são conhecimentos distorcidos e cheios de tabus que a gente aproveita para discutir e trabalhar com o grupo o lado bom desses conhecimentos"( enfermeira 3).

$\mathrm{Na}$ realidade, estamos tratando de conhecimentos, oriundos de dois tipos de cultura: a cultura acadêmica, erudita, elaborada, científica e a cultura do senso comum, construída pelo povo, revelando sua visão de mundo e da vida, dotada de um saber próprio, coerente, funcional, lógico e também dinâmico (Gramsci,1985, p. II5-9).

Em relação à saúde, as representações de nossas entrevistadas revelam significados sobe três óticas distintas: a do bem - estar, a do sofrimento e a do equilíbrio biológico. Sob a ótica do bem - estar, a saúde "é o resultado de uma vida organizada, sossegada e bem alimentada" (ANS); "saúde é ter força para trabalhar e viver feliz" (FI). Esta ótica qualifica a saúde como um valor bastante significativo e estreitamente relacionado com a própria vida. A lógica do sofrimento procura explicar a saúde através daquilo que a nega, a doença. Para (MC), "a doença é quando o sofrimento entra na vida da gente, trazendo dificuldade para viver, trazendo dor e enfermidade".

Esta representação de doença tem em sua origem causas que estão fora do corpo da pessoa doente. Reporta-nos às reflexões de Maria Cecília Minayo, 
para quem "as concepções da origem da doença por causas exógenas estão ligadas à sociedade compreendida como agressiva, opressiva, e ao modo de viver pouco saudável"(Minayo,1993, p. 178).

A terceira lógica, a do equilíbrio biológico, explica a doença, usando uma linguagem que se refere às relações sociais que a pessoa do doente mantém com outras pessoas, na convivência social. Esta lógica pode ser observada nas palavras : "eu considero doença quando a pessoa não consegue levar seu ritmo normal de vida. Doença é aquela que derruba a pessoa; aí, ela se dá conta de que algo está errado e procura um médico para tratar. "Probleminhas pequenos que a gente mesmo resolve, não é doença, faz parte da vida"(FP) .

Em sua representação de doença, dona F.P. expressa dois conceitos diferentes. Quando diz "probleminhas pequenos que a gente mesmo resolve não é doença, faz parte da vida", ela, de certo modo, reconhece e valoriza o seu conhecimento, o conhecimento popular. Ao reconhecer que "algo está errado e procura um médico para tratar", ela valoriza o conhecimento do médico, o saber científico e divide a doença em dois niveis: o que o conhecimento popular pode resolver e aquele que deve ser submetido ao saber do médico. Noutras palavras, faz um juizo de valor em que qualifica o saber do povo como limitado e subalterno. Classifica o saber do médico como saber científico e confiável, ao qual o saber comum deve estar subordinado.

A classificação desses dois saberes, senso comum e do conhecimento científico, revela duas contradições características do comportamento ingênuo: auto - desvalia e dependência. A primeira reflete a introjeção que fazem os excluídos da visão que deles têm seus opressores e a segunda, apresenta uma visão distorcida de si próprios e do mundo, que os leva a depender de seus opressores (Freire, 1981: 50-6).

\section{CONSIDERAÇÕES FINAIS}

Apesar das limitações nos dados coletados nesta pesquisa, sua análise possibilitou uma considerável aproximação da realidade empírica dos sujeitos deste estudo e permitiu construir um conhecimento novo acerca do trabalho desenvolvido no Comitê. Este caracteriza-se como um trabalho educativo, pois, há várias formas e modelos de se fazer educação e a escola não é o único e, talvez, não seja o melhor lugar onde ela possa ser trabalhada. Sob esta lógica, a educação pode acontecer espontânea e informalmente no meio das pessoas, particularmente dentro dos grupos organizados voluntariamente, a exemplo do trabalho das enfermeiras participantes deste estudo (Brandão: 10).

O Comitê parte da preocupação em fazer alguma coisa pelos indivíduos e grupos, desenvolve um trabalho participativo, valorizando os recursos que a comunidade possui, aproveitando o seu conhecimento, na perspectiva da melhoria das condições de vida da população. Isto aparece claramente no 
seguinte depoimento: "é um espaço onde eu posso ajudar esta gente a despertar, a valorizar a vida, a encorajar essas pessoas para que procurem ocupar o seu espaço e lutem por melhores condições de vida, saúde e educação, para seus filhos e para a comunidade" (enfermeira 4).

As clientes também emitem seu ponto de vista, confirmando a avaliação feita pelas enfermeiras. Esta representação pode ser resumida nas palavras : "me ajudou a despertar para os problemas da vida. Me ajudou a ver os problemas de um jeito diferente, tanto na minha família, como na comunidade" (MZS).

Em relação à perspectiva do exercício da cidadania, percebem-se algumas contradições nos depoimentos de nossas entrevistadas, a partir dos quais, duas lógicas aparecem no texto: a lógica do conformismo e a da resistência.

Sob a primeira, as pessoas, de tanto sofrerem, acabam desanimando, acomodando-se, perdendo a dignidade. São consideradas vítimas do processo de exclusão social. Esta aparece nos seguintes depoimentos: "ao iniciar meu trabalho, eu pergunto a elas o que elas acham que têm direito e, geralmente, me respondem que não têm direito a nada porque pobre não tem direitos", (enfermeira 3); "primeiro, elas nos procuram para ganhar coisas prontas, como nós não temos esses recursos, fica muito difícil segurar essas pessoas.

O conformismo aqui revelado tem três formas de expressão: a - pelo silêncio, pois, mesmo injustiçadas, excluídas do mercado de trabalho, do acesso a bens e serviços, as pessoas costumam reagir com o silêncio; b - pela resignação, a resignação com o sofrimento e a doença, aceitos como desígnios de Deus; c - pela dependência, o que exprime uma consciência reprimida.

Sob a segunda, a lógica da resistência, o povo é considerado como herói, na luta por trabalho, moradia, comida, educação, saúde e participação na vida da sociedade. Esta lógica aparece nas seguintes afirmações: "no comitê elas dão depoimento de que têm fé, acreditam que vão crescer e vão se desenvolver"; "eu acho o povo acomodado, mas, quando tem alguém que incentive, eles vão procurar solução para os problemas; o povo não tem força, precisa de apoio. Só que esse apoio não vem dos serviços públicos, pode vir de cada um de nós que moramos perto, que conhecemos o problema", (FP).

As manifestações de conformismo e resistência que aparecem nos depoimentos acima constituem a expressão de diferentes visões de mundo das pessoas que compõem os grupos de trabalho do Comitê. $O$ desafio é administrar as diferentes posições tomadas diante de questões comuns, diante de soluções alternativas para os problemas da comunidade. O desafio é ainda, acreditar na possibilidade de mudança, é acreditar no raio de luz que surge, a partir dos sinais de início do exercício da cidadania. 


\section{REFERÊNCIAS BIBLIOGRÁFICAS}

1. BRANDÃO, Carlos Rodrigues. O que é educação. São Paulo: Brasiliense, 1990

2. BRASIL. Constituição Federal de 1988, cap.III, art. 205, 9 ed. Brasília: Icone, 1988

3. COELHO, Edméia de A.C. Política de planejamento familiar em João Pessoa: análise das contradições existentes entre o discurso oficial e a prática. Dissertação de Mestradol UFPB, João Pessoa, 1997.

4. DEMO, Pedro. Cidadania menor: algumas indicações qualitativas de nossa pobreza política. Petrópolis: Vozes, 1992.

5. FERNANDES,M.G.M. Fatores contribuintes para a esquistossomose mansônica: uma proposta educativa. Dissertação de Mestrado/UFPB, João Pessoa, 1997.

6. FREIRE, Paulo. Educação e mudança. Tradução de Moacir Gadotti e Lilian Lopes. Rio de Janeiro: Paz e Terra, 1979.

7. Pedagogia do oprimido. 9 ed. Rio de Janeiro: Paz e Terra, 1981.

8. GADOTTI, Moacir. Concepção dialética da educação: um estudo introdutório. 8 ed. São Paulo: Cortez, 1992.

9. . Educação e poder. 10 ed. São Paulo: Cortez, 1991.

10. GRAMSCI, Antônio. Os intelectuais e a organização da cultura. 5 ed. Rio de Janeiro: Civ. Brasileira, 1985.

11. PARAÍBA, Governo do Estado. Crianças e adolescentes na Paraíba: saúde, educação e trabalho. João Pessoa, 1994. 